\title{
Flow simulation of River Omi, Ibadan, Nigeria, using average proportionality and linear regression methods
}

\author{
A.A. Adegbola ${ }^{1^{*}}$ and O. A. Kumolu ${ }^{2}$ \\ ${ }^{1 *}$ Department of Civil Engineering, Ladoke Akintola University of Technology, Ogbomoso, Nigeria \\ ${ }^{2}$ Department of Civil Engineering, Ladoke Akintola University of Technology, Ogbomoso, Nigeria \\ dayomos2002@yahoo.com, olumidekumolu@yahoo.com
}

\begin{abstract}
Omi river flows through Omi-Adio, Iddo Local Government Area (LGA) of Oyo State, Nigeria. The watershed hydrology of the river, over the years, has changed considerably due to the ever increasing anthropogenic activities. The resultant effect is the inundation of farmlands and flooding of residential areas in Omi-Adio township, whenever the river overflowed after heavy rain falls. Unfortunately, as with most Nigerian rivers, no discharge record exists for Omi river, making planning for provision of hydraulic structures difficult. One hundred and three years of available rainfall data and existing five years of discharge record for Ogunpa river at Molete grammar school were used to simulate surface runoff for Omi river, using average proportionality and linear regression methods. The approximation of data was based on established literature, which states that Omi and Ogunpa Rivers have similar geological and morphological characteristics. The simulation was validated with field measurements. The constant of proportionality between the two rivers was found to be 2.467. The constants: ' $a$ ' and ' $b$ ' in the linear regression equation for Omi River were computed to be 0.306445 and 0.0003036 , respectively, with a correlation coefficient of 0.98876 . The linear regression method was found to be more appropriate for Omi River at Omi Adio, Ibadan, when compared with field values. The study will assist in providing reasonable data in the design of hydraulic structures such as bridges, concrete channels, culverts and flood control structures for Omi-Adio LGA.
\end{abstract}

Keywords: Flooding, Hydrology, Watershed, Correlation, Calibration.

\section{Introduction}

The city of Ibadan, Nigeria, lies within longitudes $3^{0} 45^{\prime}$ and $4^{0} 05^{\prime}$ east and latitudes $7^{\circ} 10^{\prime}$ and $7^{\circ} 30^{\prime}$ North (Adegbola, 2006). The city of Ibadan has a population of slightly over five million; spread over an area of about 400 sq. $\mathrm{km}$. The city is naturally drained by four prominent basins, viz: Ona river towards the north and west; Ogbere river towards the east; Ogunpa river which flows through the city and Kudeti river toward the Central part of the

Fig. 1. Map of Ibadan city with Ido LGA (After Adeyemo et al., 2008)
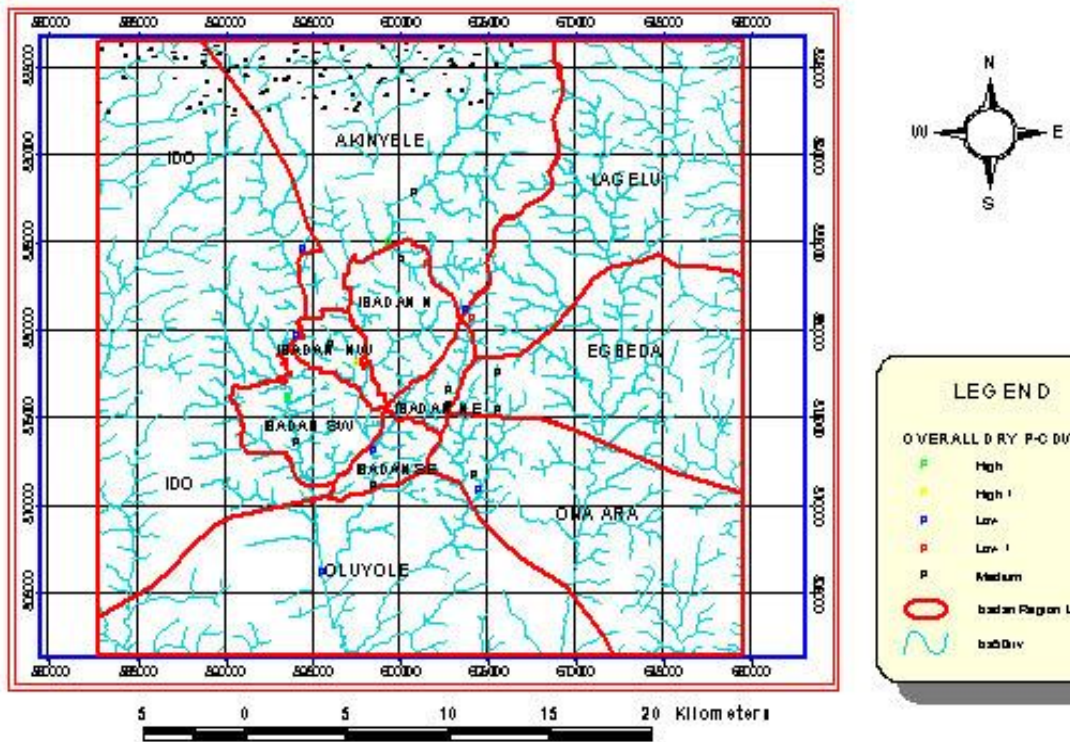

LEGEND

OVERRLL D RYY P.C DINO than thon: Lar Lat (1) Meder

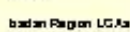
bxair

Research article (C) Indian Society for Education and Environment (iSee)
"Hydrology" http://www.indjst.org

Omi river is one of the tributaries of Ona river in Ibadan, Oyo State, Nigeria. It takes its source from between Alasa and Mele in Akinyele Local Government Area (LGA) of Oyo State, and flows south westward through Elegunde, Apoyin, Omi-Adio, etc. and joins Ona river at Gambari forest reserve. The maps of Ibadan Metropolis and drainage basins are presented in Figs. 1 and 2. The catchment area of river Omi at Ibadan Abeokuta Road in Omi township is about $123.53 \mathrm{sq}$. km.

The rainy season normally prevails from March and lasts like November, while the dry season is from December to February. The rainy season is interrupted by a short break, which usually occurs in August, but heavy rainfalls usually occur in September. According to Morawo and Awokola (2003), Ibadan has a tropical rainy climate, with an average annual rainfall of $1277.60 \mathrm{~mm}$. Six rainfall stations exist within Ibadan City, viz: University of Ibadan (UI); Old Airport Meteorological Station (MET); International Institute of Tropical Agriculture (IITA); National Institute for Horticultural Research (NIHORT); Cocoa Research Institute of Nigeria (CRIN), and Forest Research Institute of Nigeria (FRIN). Out of the six rainfall stations, according to Tokun (1998), UI, MET and NIHORT are autographic, while the others are

A.A.Adegbola \& O.A.Kumolu Indian J.Sci.Technol. 
manually monitored.

Fig. 2. Rivers Ogunpa, Ogbere and Omi (Modified after Ajibade et al., 2010)

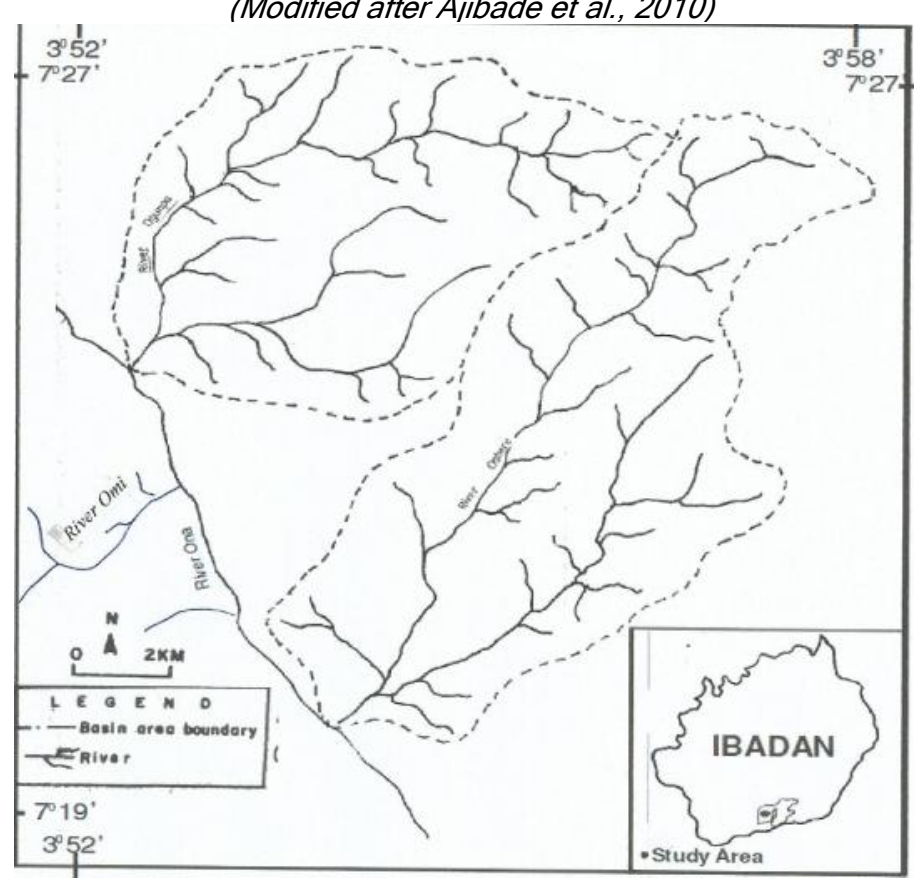

Ibadan is a commercial centre, but in recent times, has witnessed an explosion in population and an increased tempo of economic activities. In spite of regular flood tragedies in Ibadan, most rivers passing through the urban city have no flow records and Omi river in Omi-Adio is one such example. The watershed hydrology of river Omi, over the years has changed considerably due to the increasing anthropogenic activities. The aftereffect of this is the flooding and inundation of residential buildings and farmlands respectively, whenever the menacing river overflowed its banks.

One hundred and three years of available rainfall data and existing five years of discharge record for Ogunpa River at Molete Grammar School were used to simulate surface runoff for Omi river, using average proportionality and linear regression methods. The approximation of data was based on the findings of Tokun (1998), which stated that Omi and Ogunpa rivers have almost the same geological and morphological characteristics. A formulation of rainfall-runoff model for the transformation of rainfall data into river flow records for river Omi at Omi-Adio in Iddo LGA of Oyo State was carried out. The simulation was carried out with the aim of providing reasonable data for the futuristic design of hydraulic structures such as bridges, concrete channels, culverts and flood control structures, to stem the recurrent flooding in Omi-Adio LGA.

The three important phases of water transfer cycle, according to Raghunath (1991) are evaporation, precipitation and runoff. Schwab et al. (1993) presented a schematic representation of the hydrologic cycle. Parsons (2004) and Singh (1995) observed that flooding occurs when a watercourse is unable to convey the quantity of runoff flowing downstream, and that the frequency with which this occurs is described by a return period. The various factors affecting runoff from a drainage basin according to Raudkivi (1979) depend on four broad characteristics, which are: storm, meteorological, basin and storage. Raghunath (1991) found out that the average annual rainfall of a place depends on: distance from the ocean; direction of the prevailing winds; mean annual temperature; altitude of the place, and its topography. Troeh et al. (1991) discovered that the effect of vegetation cover will produce less runoff with high water infiltration in stream channels. Peak runoff decreases as the catchment area increases due to high time of concentration. Raudkivi (1979) related the runoff coefficient to soil types.

Dingman (2002) classified hydrologic models as a representation of a portion of the natural or human constructed world, which can initially be classified as physical, analog or mathematical. A mathematical model was defined as consisting of explicit sequential set of equations and numerical and logical steps, which converts numerical inputs to numerical outputs. Dingman (2002) opined that hydrologic models have arisen as a result of the complexity, variability and limited availability of spatiotemporally distributed hydrological, climatic, soil and land-use data. Boughton (1993) stated that hydrologic models simplify representations of actual hydrologic systems, predict hydrologic responses and allow to study the functions and interaction of various inputs, and in so doing gain a better understanding of events. Raghunath (1991) outlined that runoff from rainfall may be estimated by empirical formulae, curves and tables, infiltration and rational methods, overland flow hydrograph and unit hydrograph.

Linear Auto Regressive Moving Average (ARMA) models for hydrologic time series forecasting and simulation have gained limited acceptance with practitioners. Yakowitz (1985) considered a finite order continuous parameter Markov Chain as an appropriate model for hydrologic time series. It was observed that discretization of the state space can quickly lead to an unmanageable number of parameters or poor approximation of the transition functions, while the ARMA approximations to such a process call for restrictive distributional and structural assumptions. Tong (1990) provided motivation for nonlinear time series analysis methodology and for nonparametric modeling and visualization of time series. A daily river flow was used to illustrate that data with sudden jumps; time irreversibility, asymmetric joint distributions, persistence and state dependent correlation between lagged flows do not support the assumptions inherent in classical linear ARMA modeling. Yakowitz and Karlsson (1987) provided theoretical basis for Nearest Neighbor (NN) regression for prediction of time series, and specifically for rainfall-runoff modeling. Galeati (1990) showed that the simple NN 
predictor provided lower mean square error predictions of daily mean inflow to an Italian reservoir relative to an autoregressive model with exogenous inputs that was coupled to physically based, calibrated, rainfall-runoff and snow cover evolution models.

Smith (1991) and Smith et al. (1999) presented some interesting applications of Yakowitz's ideas that exposed the flexibility of nonparametric methods for seeking relationships between arbitrary functions of possibly linked data sets. HYBSCH model was developed by Miegel (1988), and was found to be most appropriate by Taffa (1989), for the Central Highlands of Ethiopia. The Linear Pertubation Model (LPM) was suggested by Nash and Barsi (1983) for rainfall-runoff modeling. The potentials of LPM were demonstrated for daily rainfallrunoff modeling on large catchments. However, Kothyari et al. (1993) showed that LPM was more accurate for monthly than for daily runoff simulation, particularly for medium sized catchments. Raghunath (1991) demonstrated that flow can be estimated for sites where streamflow records are not available by multiple regression techniques using the drainage basin and climatic characteristics as independent variables. The regression constant and coefficient are calculated using streamflow data from gauged streams. Tokun (1998) extended short stream flow records by using linear regression methods, where average monthly rainfall was regressed against average monthly runoff, and a straight line relationship obtained.

\section{Methodology}

The governing equation for the rainfall-runoff modeling were derived by using linear regression methods as outlined by Tokun (1998), whereby average monthly rainfall was regressed against average monthly runoff viz:

$Q_{n}=A_{n} R_{n}+C$

Where, $Q_{n}$ is the estimated runoff in month, $n ; R_{n}$ is rainfall in month, $n ; A_{n}$ is the regression coefficient and $C$ is the regression constant. For good correlation, average monthly net rainfall was regressed against average runoff, and equation 2 becomes:

$Q_{n}=A_{n} R_{n}^{1}+C$

Where $R_{n}^{1}=$ Net Rainfall = Rainfall,

$\mathrm{R}_{\mathrm{n}}$ - Evapotranspiration, $\mathrm{ET}_{\mathrm{n}}$

Equations 2 and 3 indicates that runoff, $Q_{n}$ is a function of the previous rainfall, $R_{n}$. An improved lumped parameter rainfall-runoff relationship was allowed using an established procedure, thus:

$Q_{n}=A_{n} R_{n}+A_{n-1} R_{n}+A_{n-2} R_{n-2}+A_{n-k} R_{n-k}$ (3)

Where $R_{n}$ is the net or effective rainfall values in months $n, n-1, n-2, \ldots n-k ; A n, A_{n-1}, \ldots . A_{n-k}$ is the regression coefficient to be evaluated by multiple regression analysis for each of the 12 months, and $\mathrm{C}$, is the regression constant. Equation 3 is the governing equation for the historical rainfall-runoff simulation of Omi River at Omi Adio. The Thorn waite nomogram was used to calculate the potential evapotranspiration for the study area, as follows:

$\mathrm{PET}=\mathrm{PE}_{\mathrm{x}} \mathrm{DT} / 360 \mathrm{~mm}$

Where PET is the potential evapotranspiration; $P E_{x}$ is theoretical potential evapotranspiration based on 30 days and 12 hours sunshine per day (calculated for Thornwaite Nomogram); $\mathrm{D}$ is the number of days in the month and $\mathrm{T}$ is the average number of hours between sunrise and sunset in the month. The values of potential evapotranspiration used in the study were collected from OSOT Associates Consulting Engineers, Ibadan. Topographical maps, rainfall data, stream discharge data and other meteorological data, such as temperature, relative humidity, wind speed, sunshine hours were collected from the map depot, Oyo State, old airport, Samonda Ibadan, OSOT Associates, and the published literature.

There was no gauging station on Omi River; hence no runoff data for the location exist. However, since Omi and Ogunpa rivers have similar geological and morphological characteristics, the flow records for Ogunpa river at Molete were approximated to compute the Omi river flows using averaging or proportionality method. This exercise is consistent with the work of Raghunath (1991) and Tokun (1998). Temporary runoff gauging stations were sited on rivers Omi at Omi Adio and Ogunpa at Molete Bridge to establish a relationship of the form:

$\mathrm{Q}_{\mathrm{m}}=\mathrm{K}_{\mathrm{a}} \mathrm{Q}_{\mathrm{o}}$

Where $Q_{m}$ is the measured discharge for Omi river; $Q_{0}$ is the measured discharge for Ogunpa river and $K_{a}$ is the proportionality constant to be estimated. With this relationship in equation 5 , the flow for Omi river can be computed from available historical data.

Stream gauge heights were converted to actual flow using the relationship:

$\mathrm{Q}=\mathrm{AV}$ or $\mathrm{Q}=\mathrm{b} d \mathrm{~d}$

Where; $Q$ is the discharge (stream flow) in $\mathrm{m}^{3} / \mathrm{s}$

$A$ is the cross-sectional area of the box section in $\mathrm{m}^{2}$.

$b$ is the width of box section in $m$.

$d$ is the depth or height of the box section water level (gauge height) in $\mathrm{m}$.

$\mathrm{V}$ is the mean velocity of flow in $\mathrm{m} / \mathrm{s}$.

The mean velocity of flow (V) was determined by velocity measurements, using surface floats. The time (t) taken by the float to travel a known distance (L) was measured and the surface velocity was calculated. This was repeated several times per day to arrive at the mean velocity of each float across the culvert section.

The measured discharge data of River Omi at Omi Adio was regressed against the measured data at Ogunpa river, using the equation:

$Y=a+b X$

where $a$ and $b$ are the constants to be determined; $r$ is the correlation coefficient for the regression; $Y$ equals $Q_{m}$, which equals Omi river flow and $X$ equals $Q_{0}$, which equals Ogunpa river flow. Equation 7 can be rewritten as:
Research article

COIndian Society for Education and Environment (iSee)
"Hydrology"

http://www.indjst.org
A.A.Adegbola \& O.A.Kumolu Indian J.Sci.Technol. 
$Q_{m}=a+b Q_{o}$

Ogunpa river had only five years of measured data. Since this was observed to be too small for any useful planning, the five years record was extended using linear regression method. This was accomplished by firstly regressing the rainfall values of 1990 to 1994 against the Ogunpa discharge values for 1990 to 1994, with the following relationship:

Qo $=\mathrm{a}+\mathrm{bR}$

Where $a$ and $b$ are constants to be determined and $R$ is the rainfall value. It was observed from the exercise that the 1993 records had the highest correlation coefficient, and was thus used to derive the discharge equation by substituting coefficients into equation 9 . The resulting relationship was used to extend Ogunpa river flow record from 1905 to 2008. Equation 8 was thereafter used to compute the runoff data for Omi River with the same record length.

\section{Results and discussion}

The Ibadan rainfall data from 1905 to 2008 are presented in Fig. 3. The five-year measured discharge data for Ogunpa river at Ibadan Grammar School Road, Molete, is presented in Fig. 4. The constant of proportionality in equation 5 is 2.467 . Substituting this value in equation 5 , we have:

$\mathrm{Q}_{\mathrm{m}}=2.467 \mathrm{Q}_{\mathrm{o}}$

(10)

Fig. 3. Ibadan monthly rainfall data

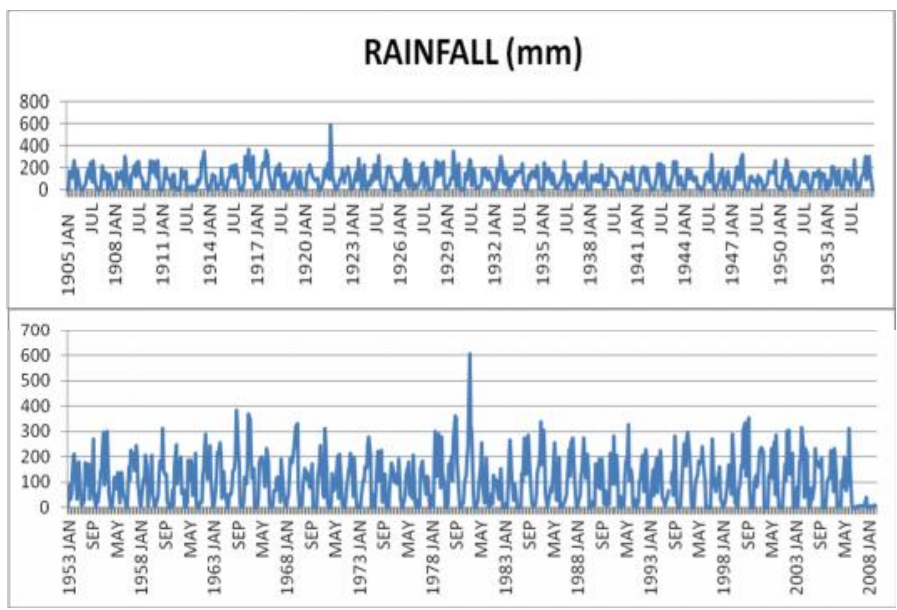

Fig. 4. Measured discharge record for Ogunpa River at Molete

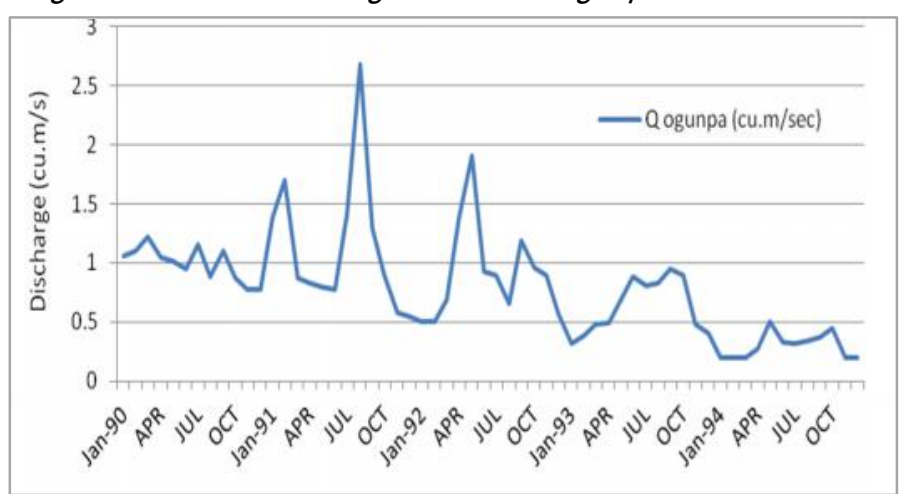

Fig. 5. Extension of Ogunpa river flow record

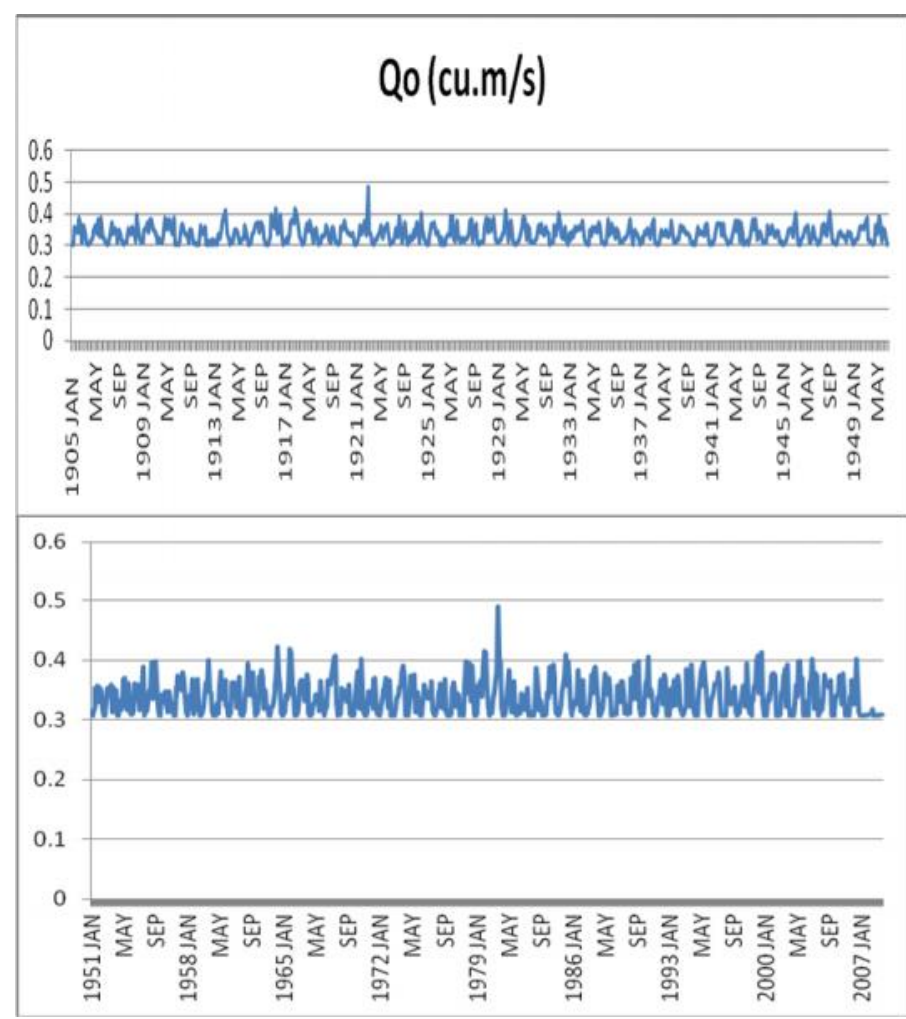

Fig. 6. Computed river flow record for river Omi using Average / proportionality and linear regression methods

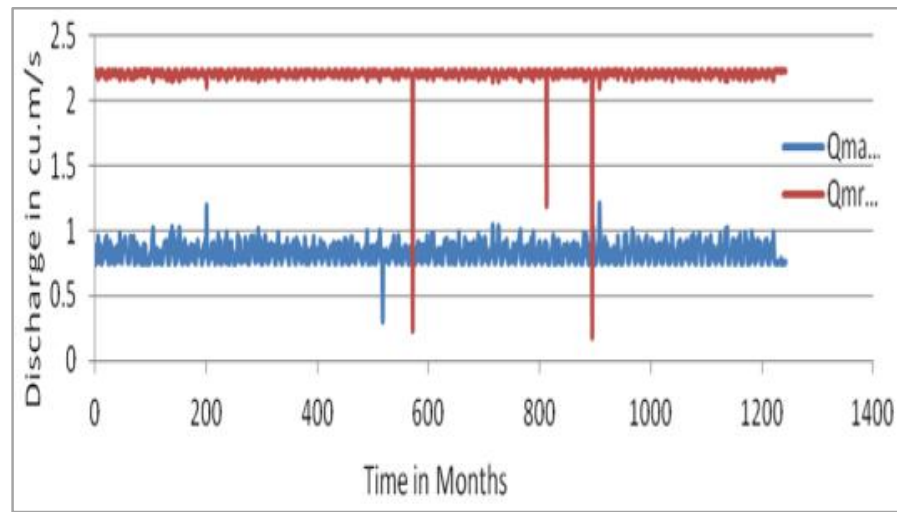

Substituting the values of the regression analysis in equation 8 , we have:

$\mathrm{Q}_{\mathrm{m}}=2.44221-0.69177 \mathrm{Q}_{\mathrm{o}}$

Substituting the 1993 results with the highest correlation coefficient in equation 9 , we have:

Qo $=0.306445+0.0003036 \mathrm{R}$

The extension of Ogunpa river flow record from 1905 to 2008 is presented in Fig. 5. The computation of runoff data for river Omi, using the relationship in equations 10 and 11 , for average proportionality and regression methods respectively, is presented in Fig. 6. The correlation coefficient was 0.98876 . The linear regression method was found to be more appropriate for Omi river at Omi Adio, Ibadan.
Research article

COIndian Society for Education and Environment (iSee)
"Hydrology"

http://www.indjst.org
A.A.Adegbola \& O.A.Kumolu Indian J.Sci.Technol. 


\section{Conclusions and recommendation}

The following conclusions are drawn from the study:

(i) Ibadan rainfall data from 1905 to 2008 , compiled by Akintola (1986), was used to derive runoff data of the same length for Omi river, using average proportionality and regression methods.

(ii) There was no gauging station on Omi river; hence no runoff data for the location exist. However, since Omi and Ogunpa Rivers have the same geological and morphological characteristics, the flow records for Ogunpa river at Molete were approximated to compute the Omi River flows. The approach is consistent with published literature.

(iii) Rainfall and runoff data are very crucial in design of flood mitigation structures on the Omi river.

(v) The linear regression method was found to be more appropriate for Omi river at Omi Adio, Ibadan.

It is recommended that permanent flow recording stations should be installed along the Omi River channel course to assist in quantifying reasonably discharge floodwater for the purpose of control and provision of suitable hydraulic structures such as bridges, concrete channels, culverts and flood mitigation structures for Omi Adio township.

\section{References}

1. Adegbola AA (2006) A review on safe water provision for residents of Ibadan city. Sci. Focus. 11(1), 139146.

2. Boughton WC (1993) A hydrograph based model for estimating the water yield of ungauged catchments. Hydrology \& Water Resources Sym. Institution of Engineers Australia, Newcastle. pp: 317-324.

3. Dingman SL (2002) Physical hydrology. $2^{\text {nd }} E d$., Prentice Hall, NJ.

4. Galeati G (1990) A comparison of parametric and non-parametric methods for runoff forecasting. Hydrol. Sci. J. 35(1), 79-94.

5. Kothyari UC, Aravamuthan V and Singh VP (1993) Monthly runoff generation using the linear perturbation model. J. Hydrol. pp: 144.

6. Miegel K (1988) Erfassung hydrologischer prozesse innerhalb eines entscheidungsstutzenden

Programms Monatsund Schlagbezogemen Modllierung Von Wasser-und stickstoffhaushalt in Gewassereinugsgebieten. Dissertation, Technic. Univ. of Dresden. pp: 105.

7. Morawo OA and Awokola OS (2006) Modelling of runoff in Bodija, Ibadan. Nigeria. Sci. Focus. 11(1), 91-102.

8. Nash JE and Barsi BI (1983) A hybrid model for flow forecasting on large catchment. J. Hydrol. 10(3), 282290.

9. Parsons RC (2004) Born down by the water. Flanker Press Ltd., Canada.

10. Raghunath HM (1991) Hydrology: Principle, Analysis and design. $4^{\text {th }}$ ed., Karnataka, Wiley Eastern Ltd.
11. Raudkivi AJ (1979) Hydrology: An advanced introduction to hydrological processes and modeling. Pergamon Press. UK.

12. Schwab GO, Fangmeier DD, Elliot WJ and Frevert RK (1993) Soil and water conservation engineering. John Willey \& Sons, Inc.

13. Singh RB (1995) Role of geographical monitoring and forecasting in ecosystem modelling and management: An introduction. Global Environ. Change - Perspectives of Remote Sensing \& Geog. Info. Sys., Intl. Geograph. Union. Taylor \& Francis, UK.

14. Smith LA (1991) Applied chaos: Quantifying complex systems. Info. Dynamics. ed. H. Atmanspacher, et al. NATO ASI Series B. Plenum Press, NY. 256, 97-102,

15. Smith LA, Ziehmann C and Fraedrich K (1999) Uncertainty dynamics and predictability in chaotic systems. Quart. J. Royal Meteorol. Soc. 125, 28552866.

16. Taffa $T$ (1989) Hyrologische untersuchungen an ausgeWahlten Einzzugsgebieten in Zentralhochland Athiopiens als Voraussetzung Zur besseren Bewirtschaftung der Wasserressourcen. Dissertation, Rostocia Univ. pp: 135.

17. Troeh FR, Hobbs JA and Donahue R (1991) Soil and water conservation. $2^{\text {nd }}$ Ed., Englewood Cliffs (NJ): Prentice Hall.

18. Tokun A (1998) Long term water option for Ibadan city. Report of Bi-Monthly Seminar of OSOT Assoc. Consulting Engineers, Ibadan.

19. Tong H (1990) Non-linear time series. Dynamical Sys. Approach. Oxford University Press. Oxford.

20. Yakowitz S (1985) Modelling uncertainty. Int. Series in Operations Res. \& Manage. Sci. Springerlink. 46(1), 1-11.

21. Yakowitz $S$ and Karlsson M (1987) Nearest neighbour methods for time series with application to Rainfall-Runoff prediction. Stochastic Hydrol., MacNeil JB, Humphries GH (eds). Reidel: Hingham, MA. pp: 146-160. 